\title{
La cuestión del aborto. Una perspectiva filosófico-jurídica de un problema ético-moral*
}

\author{
ADRIÁN RENTERÍA DÍAZ \\ Università degli Studi dell'Insubria \\ Facoltà di Giurisprudenza/Istituto di Scienze Giuridiche (Como, Italia) \\ renteria@fildir.unimi.it
}

\begin{abstract}
RESUMEN: El objetivo principal del artículo es hacer notar la dimensión jurídico-normativa del problema del aborto, considerando que acentuar excesivamente su dimensión éticomoral conduce a una estéril contraposición que impide una discusión serena del aborto y de su dimensión irremediablemente pública. En este sentido, aún reconociéndole su perspectiva moral, en el artículo se plantea la posibilidad de pensar el aborto como una conducta que pueda reconducirse a un modelo de regulación jurídica "blando", donde la perspectiva moral del legislador no adquiera las características de una moral común, igual para todos, y que, por el contrario, mediante la modalidad jurídica del permiso, cada individuo ponga en acto su propia convicción moral. De ahí puede surgir una legislación en la que el aborto no sea objeto ni de un deber jurídico ni de una prohibición: abortar o no abortar, en este modelo de regulación jurídica, son decisiones que los individuos toman con base en sus propias convicciones.
\end{abstract}

PALABRAS CLAVE: aborto, derecho, permiso, persona

El interés teórico — filosófico y jurídico, además de moral— acerca de la controvertida cuestión del aborto se abre cada vez más espacios importantes dentro de la reflexión en México. Aunque quizá un tanto retrasada en relación con el debate que en muchas otras latitudes ha conducido al legislador a revisar el conjunto de disposiciones jurídicas que regulan esta delicada cuestión social, también en México la discusión finalmente parece haberse inaugurado: filósofos, médicos, bioeticistas, hombres de la Iglesia, grupos de mujeres están desde hace tiempo examinando el problema, contribuyendo de un modo o de otro a que el problema finalmente emerja, salga a la luz, fuera de la clandestinidad donde siempre se lo ha relegado.

Sin embargo, en este incipiente debate, a mi juicio, subyacen algunos "vicios" metodológicos de fondo — de naturaleza terminológico-lexical— que

* Durante su estancia sabática en Italia, sostuve vivaces discusiones con Rodolfo Vázquez, del Departamento de Derecho del ITAM, sobre versiones precedentes de este trabajo, y por ello le estoy muy agradecido, si bien no creo que mis respuestas verbales a sus objeciones, ni el resultado escrito final, sean de su completo agrado. 
introducen algunos factores de confusión conceptual cuyo efecto es oscurecer el núcleo del problema. Uno de los objetivos que aquí se persiguen es precisamente esclarecer los términos del debate en relación con el concepto de aborto, con la esperanza de poder disipar algunos malentendidos. Las observaciones siguientes nacen a raíz de una preocupación teórica sobre el tema del aborto, que desde luego se conecta también con lo que sucede en la realidad concreta, sobre todo en una sociedad como la mexicana, donde el aborto constituye, formalmente, un delito. De aquí, entonces, un segundo objetivo: a partir de una reciente investigación, ${ }^{1}$ donde se examina el problema del aborto en términos de una verdadera contraposición entre diversas concepciones acerca de la idea de persona y de la moral, se tratará de hacer evidente cómo la discusión en esos términos es sustancialmente insatisfactoria, pues no hace sino reforzar el conflicto ideológico sin proponer alternativas viables para su recomposición. Alternativas, por el contrario, que pueden descubrirse en una reflexión que no ponga en el centro de la atención el "resbaloso" terreno de la idea de persona, y que no oponga una visión moral a otra visión también moral, sino que concentre el interés en el universo jurídico-normativo representado por las disposiciones jurídicas, sus finalidades, sus instrumentos, sus resultados. No se trata tanto de negar la valencia moral del aborto, siendo ésta evidente en la percepción de las personas; se trata más bien de afrontar la cuestión del aborto como un problema público y de política del derecho, para considerarlo más bien en lo relativo a su disciplina concreta, sus resultados, sus efectos, para proponer posteriormente modalidades diferentes en cuanto a su regulación. Con ello quizá se despojaría al problema un tanto de su ropaje ideológico y moral (o, mejor dicho, moralizante y moralista), concentrando la reflexión en un aspecto sobre el cual los términos del (des)acuerdo resulten verificables y discutibles en mayor medida.

\section{UN ACERCAMIENTO AL CONCEPTO DE ABORTO}

En un sentido muy general, por 'aborto' se suele entender aquel evento que, verificándose antes de que el proceso de gestación llegue a su fin, tiene como resultado la interrupción de la gravidez, la muerte del producto en gestación y su expulsión fuera del cuerpo del ser que le proporcionaba la fuente para su desarrollo. Muy oportunamente, en este nivel del análisis se ha intentado distinguir entre aborto humano y aborto no humano, tomando en consideración precisamente el hecho de que este tipo de eventos no

1 Me refiero al escrito de Margarita Valdés, "El problema del aborto: tres enfoques", en Rodolfo Vázquez (comp.), Bioética y derecho. Fundamentos y problemas actuales, ITAM-FCE, México, 1999, pp. 129-150. 
son exclusivos del género humano. ${ }^{2}$ Huelga decir que el objeto de estas observaciones es el concepto de aborto que concierne al género humano. Indudablemente, ello supone una visión antropocéntrica del problema, lo que podría quizá generar algún sentimiento crítico en aquellas áreas del pensamiento donde se comienza a hablar de derechos en relación con seres no humanos: ${ }^{3}$ no disponiendo de una respuesta articulada, adecuada al espíritu de este trabajo, correré ese riesgo.

La noción que surge es aún muy general, pues aunque ya precisa que se habla de aborto en relación con los seres humanos, deja todavía abiertas demasiadas cuestiones. En primer lugar, como es evidente, no hemos distinguido aún entre el aborto voluntario (o inducido, como algunos prefieren llamarlo) y el aborto involuntario. La línea que los separa está marcada por el uso o no uso de medios "artificiales" mediante los cuales se realiza el aborto. Por 'artificial' estoy entendiendo, en este contexto, todo medio que se distinga del desarrollo natural del embarazo (o que se oponga a él), es decir, que presuponga la intervención humana. Será, en este sentido, voluntario el aborto que se produce utilizando medios artificiales, e involuntario el que es resultado de un evento natural durante el embarazo.

La distinción entre aborto voluntario y aborto involuntario podría también, a primera vista, dar la impresión de ser suficiente para una adecuada comprensión de la problemática del aborto. Sin embargo, si damos una ojeada al estrato más profundo del concepto, nos percataremos fácilmente de que no es así, que se hace necesario establecer distinciones ulteriores.

Hablemos primero del aborto voluntario. Habitualmente, cuando se habla del aborto en este sentido, que es el que mayormente genera polémica, tendemos a pensar en la interrupción de la gravidez que se verifica en un estadio de desarrollo posterior al momento en que el óvulo fecundado se "anida" en la pared del útero. En el imaginario colectivo, en efecto, las personas hablan del aborto y se imaginan al médico (o a la comadrona) que materialmente "extrae" del cuerpo de la mujer en cuestión un producto

\footnotetext{
2 Aunque un tanto tímidamente, tal intención parece estar presente en el artículo de Margarita Valdés ya citado; véase especialmente la p. 129.

3 En ese sentido, cfr. al menos: P. Singer, Animal Liberation, Nueva York, 1977 (Avon Books, 1975), trad. al italiano: Liberazione animale, Milán, 1991; T. Regan, The Case for Animal Rights, The Regents of the University of California, 1983, trad. al italiano: I diritti animali, Garzanti, Milán, 1990; P. Singer y T. Regan (comps.), Animal Rights and Human Obligations, Prentice-Hall, Englewood Cliffs (N.Y.), 1976; J. Feinberg, "The Rights of Animals and Unborn Generations", en W.T. Blackstone (comp.), Philosophy and Environmental Crisis, University of Georgia Press, Athens, 1974, también incluido en J. Feinberg, Rights, Justice, and the Bounds of Liberty: Essays in Social Philosophy, Princeton University Press, Princeton, 1980; S. Castignone (comp.), I diritti degli animali, Génova, 1985 (2a. ed., 1988); id., Povere bestie. I diritti degli animali, Marsilio, Venecia, 1997.
} 
ya en un estadio por lo menos avanzado, si no es que ya formado, en el que incluso se pueden distinguir partes rudimentales del cuerpo. A esta visión un tanto reductiva, que presenta exclusivamente su aspecto "truculento", sin duda contribuye una buena parte de la campaña que en todas partes del mundo conducen aquellos grupos que se oponen a toda legislación que no reprima el aborto. Lo que no se distingue adecuadamente en esta perspectiva es lo que sucede antes de que el óvulo fecundado se fije en la pared del útero. Quienes se oponen al aborto, en efecto, fundamentan su posición en la convicción de que la vida humana se inicia desde el momento mismo de la concepción; ${ }^{4}$ de lo cual se sigue que se considere profundamente equivocado interrumpir el desarrollo de un ser inocente (asesinar, dicen algunos). Si se concede, no sin alguna perplejidad, que la vida humana comienza en el momento de la concepción, se debe pedir cuentas entonces de todo aquello que sucede antes de que el óvulo fecundado se "anide" en el útero. No se entiende, en efecto, la indulgencia de muchas personas que abiertamente se declaran contrarias al aborto al considerar algunos medios anticonceptivos (el dispositivo intrauterino o DIU, por ejemplo) ${ }^{5}$ que tienen como finalidad impedir la fijación del óvulo fecundado en el útero. El examen atento de estas diferencias debería conducir a generar una mayor sensibilidad en la opinión pública respecto de la idea que se tiene del aborto, y a buscar una mayor coherencia entre quienes se declaran contrarios a él, pues es a todas luces evidente que la discusión generalmente no se concentra en el aspecto apenas señalado, favoreciendo así la polémica centrada en el aspecto que en mayor medida impacta en el grande público, o sea el aborto voluntario que se realiza una vez que el óvulo se ha "anidado" en el útero. Una mayor atención a la diferencia subrayada podría determinar, de algún modo, al menos la eliminación de una doble moralidad, del abismo que hoy parece infranqueable entre lo que se declara y lo que se hace, entre la teoría y la praxis.

Por otro lado, también la noción de aborto involuntario es susceptible de diferenciaciones no irrelevantes para una mejor comprensión del con-

${ }^{4}$ Es evidente que esta convicción deriva directamente de las enseñanzas de la Iglesia Católica, acogida por quienes se reconocen en ellas. Véanse, por ejemplo, los siguientes documentos papales: Congregazione per la dottrina della fede, Dichiarazione sull'aborto procurato, 18 de noviembre de 1974, pp. 12-13; Evangelium vitae. Il valore e l'inviolabilità della vita umana, carta encíclica de Juan Pablo II, 25 de marzo de 1995, Paoline edizioni, Milán, 1995, especialmente las pp. 81-96. También véase, en la misma perspectiva religiosa pero no carente de aspectos críticos: Norman M. Ford, When Did I Begin? Conception of the Human Individual in History, Cambridge University Press, Cambridge, 1988, trad. al italiano: Quando comincio io? Il concepimento nella storia, nella filosofia e nella scienza, Baldini \& Castoldi, Milán, 1997.

5 Y también la píldora del día después (o RU-486), anticonceptivo de emergencia cuyo uso se recomienda al día siguiente de cuando se ha tenido una relación sexual no protegida. 
cepto de aborto y de su problemática. Procedamos ahora a hacer una breve incursión en la noción de voluntad o de acto voluntario.

Hablando de aborto voluntario, es evidente que con 'voluntad' nos referimos en realidad a dos "sujetos" diferentes: la mujer que aborta - ya sea cuando ella misma se induce el aborto, ya sea cuando otra persona lo realiza- y el médico (o quien funja como tal) que en ciertas ocasiones practica el aborto. Por otro lado, si hablamos de aborto involuntario, a esos dos sujetos habría que sumar la "involucración" de un tercero: la naturaleza. Veamos de qué modo y cómo ello puede explicar que se pueda hablar de una distinción en la noción de aborto involuntario.

Se dijo anteriormente que es involuntario el aborto que es consecuencia de un evento natural sucedido durante el lapso en el cual el óvulo fecundado (embrión, cigoto, feto) permanece dentro del cuerpo de la mujer. Ahora bien, lo que se deseaba subrayar con el vocablo 'natural' era, sin lugar a dudas, la ausencia de voluntad por parte del sujeto cuyo cuerpo "hospeda" el ser en ciernes: la mujer. La voluntad de la mujer es, pues, determinante para calificar como voluntario o involuntario el aborto, aunque en el caso de este último nos obliga a tomar en cuenta al agente cuya "acción" lo hace posible. Así las cosas, en efecto, no es del todo irrelevante pensar en una situación en la que una mujer es obligada (mediante la fuerza o mediante una presión diferente, psicológica por ejemplo) a abortar. En este caso es evidente que nos encontraríamos frente a un hecho reprobable fácilmente reconducible a una acción penal que - supongo- contará con el acuerdo general. Por otra parte, en ese mismo orden de ideas podemos imaginar la situación que se configura cuando el aborto se produce como consecuencia de una "voluntad" natural, aun contra los deseos de la mujer que desea continuar su gravidez. Es ciertamente arduo hablar de una "voluntad" de la naturaleza, y sin embargo con ello solamente quiero destacar las no infrecuentes situaciones en que se producen aquellos abortos que se suelen llamar espontáneos, cuyas causas no pueden ser adscritas ni a la mujer embarazada ni a la acción de otra persona. En algunos casos, en efecto, se produce la unión de los gametos femenino y masculino, pero el óvulo fecundado no logra "anidarse" en el útero de la mujer y es expulsado del cuerpo de ésta, casi sin que ella haya percibido nada de lo que sucedió en su organismo. También, como es sabido, aun cuando el óvulo se anide en el útero, dando inicio al proceso gestativo vero y propio, durante el desarrollo sucesivo - por razones y modalidades no del todo claras a la ciencia médica- el proceso se interrumpe y se produce un aborto espontáneo sin que haya intervenido una acción voluntaria de la mujer o de otra persona. ¿A quién pedirle cuentas en circunstancias de este tipo? 
Las observaciones precedentes nos ponen ahora en condiciones mejores para identificar un núcleo de significado más preciso del término 'aborto', lo que sin duda también influye en una mayor comprensión de la problemática que se le conecta. La noción de aborto que constituye el objeto de debate entre abortistas y antiabortistas, por decirlo con una fórmula sintética, es la interrupción voluntaria del embarazo; lo que está en juego es la voluntad de la mujer embarazada, tanto si ella misma se induce el aborto como si quien lo realiza es una persona diferente. Además, en esta noción de aborto se suele excluir el tipo particular de aborto voluntario que se realiza mediante instrumentos normalmente caracterizados como anticonceptivos, si bien, como hemos visto, quizá se los podría calificar más bien como abortivos. ${ }^{6}$ Por otro lado, y es la última observación terminológica, existe aún un campo que se debe investigar: el relativo al tiempo, al desarrollo gradual del óvulo fecundado en el vientre materno y a las diversas valoraciones que en general suscita un aborto según que se verifique en un estadio o en otro. En efecto, así como el resultado abortivo que deriva del uso de medios "anticonceptivos" como la espiral no genera demasiadas preocupaciones teórico-morales, tal vez porque sucede en un estadio inicial, y en ocasiones sin que la mujer tenga conciencia plena de lo que sucede, de igual modo esta conceptualización del embarazo en etapas sucesivas ha conducido a muchas personas a calificar de modo diferenciado el aborto: a mayor desarrollo del embrión corresponde un juicio mayormente negativo, y a menor desarrollo un juicio negativo más atenuado.

Es ahora el momento, en virtud de lo apenas asentado, de hacer explícita mi posición con respecto a la cuestión del aborto, además de la estrategia que sugiero para su análisis. Pues bien, intentaré proporcionar algunas razones en favor de una legislación permisiva del aborto, y lo trataré de hacer exclusivamente a partir de consideraciones de carácter jurídico, sin caer en la "trampa" que —según mi opinión- esconden expresiones como "inicio de la vida", "el feto es una persona humana", "inviolabilidad de la vida humana" y similares, y que pueden generar malentendidos en el debate y en la percepción del problema. ${ }^{7}$ Por otra parte, por razones que espero sean evidentes en el curso del trabajo, me refiero a la idea de aborto como acción voluntaria realizada dentro de los tres primeros meses de gestación.

${ }^{6}$ Véase una visión más detallada en M. Mori, Aborto e morale, Il Saggiatore, Milán, 1996, en especial la p. 37 y ss.

7 A su vez, tales consideraciones jurídicas pueden justificarse o no a partir de argumentaciones ulteriores; por ejemplo, relativas a la incidencia de los abortos clandestinos (al respecto, véase la n. 16, infra), o bien con base en argumentaciones de carácter teleológico ( $c f r$. $\S$ VII). 


\section{LAS POSICIONES EN CONFLICTO}

Es a todas luces evidente que las posiciones que se enfrentan en la problemática del aborto pueden reconducirse sustancialmente a dos: por comodidad expositiva por ahora me refiero a ellas como posición "antiabortista" y posición "abortista". En la primera confluyen las tesis de quienes sostienen que el aborto constituye un error moral, que es intrínseca y moralmente un error interrumpir un embarazo, y que, en consecuencia, las disposiciones de un Estado deben prohibir su práctica, reforzando la prohibición con la amenaza de la coacción. En su versión más extrema, y que sin embargo no creo que resulte caricaturizada excesivamente, el aborto es inmoral, y por ende injustificado, aun cuando el feto se vea afectado por problemas de malformación genética, o bien, aunque la continuación del proceso de gestación ponga en peligro la vida de la mujer; y, aún más, el juicio moral negativo no cambia en casos de violación e incesto. En todo caso, según esta posición, la mujer puede optar por la alternativa de dar el bebé en adopción cuando enfrenta un embarazo indeseado.

Ésta es la perspectiva de quienes se oponen al aborto; su fuerza en el debate ha consistido en generar en el grande público ${ }^{8}$ —no siempre suficientemente reflexivo y atento- una imagen "cómoda" de quienes se oponen a ella; "cómoda", obviamente, en cuanto circunscribe la posición "abortista" en márgenes definitorios muy estrechos, tratando de presentarla como su contrario, casi como si se tratase de una imagen reflejada en un espejo. En otros términos, las notas que caracterizan la posición del antiabortista han contribuido en buena manera a configurar una imagen de sus oponentes simple y sencillamente mediante una contraposición: si el "antiabortista" combate el aborto, entonces el "abortista" está a favor del aborto. En realidad, soy de la idea de que la imagen del "abortista" que resulta de esta contraposición determina de hecho una sucesión de errores metodológicos, que ello favorece una contraposición ideológica difícilmente resoluble de manera racional, y que - como apuntaba antes- le "hace gordo el caldo" a la posición antiabortista.

Lo que deseo afirmar es muy sencillo: que el "abortista" no es necesariamente una persona a favor del aborto, que su posición no implica sic et simpliciter un compromiso con un juicio moral positivo del aborto que se pretende hacer extensivo a todos. Por otra parte, a mi parecer, no existe una simplificación semejante en el caso de la posición antiabortista, pues quien se reconoce en ella sí emite -explícita o implícitamente- un juicio moralmente negativo del aborto, y trata de hacerlo extensivo. Para tratar de demostrar lo anterior basta, por un lado, con prestar atención a lo que los

8 Aunque a veces también entre quienes se interesan en la cuestión desde una postura principalmente crítico-teórica. 
juristas denominan modalidades jurídicas, a saber, las modalidades mediante las cuales un ordenamiento jurídico regula la sociedad, y, por el otro, con relacionarlas con las recientes reflexiones en torno al tema de los modelos de regulación jurídica.

\section{EL DERECHO Y LA REALIDAD. DOS MODELOS DE REGULACIÓN}

La realidad social puede relacionarse de cuatro modos con el derecho, tres de ellos más o menos directos. Tal relación, está claro, se instaura a partir de la manera en que un determinado ordenamiento jurídico califica un evento (acción, conducta, comportamiento) que tiene lugar en la realidad. La manera más o menos directa en que las disposiciones jurídicas pueden calificar una acción se articula de tres formas: permitiendo que se realice, obligando a que se realice o prohibiendo que se realice. La manera indirecta, por otra parte, se verifica simplemente cuando el ordenamiento jurídico omite cualquier señal en relación con una acción: ni establece que exista la obligación de realizarla, ni que se deba evitar realizarla, ni siquiera que su realización dependa de la voluntad de las personas: en otras palabras, una acción no está considerada por el ordenamiento jurídico. Se trata del campo de lo no jurídico.

Las acciones que el derecho no califica jurídicamente constituyen una categoría particular, pues en general pertenecen, por un lado, a una esfera del comportamiento humano que no tiene repercusiones notables en la vida común; en consecuencia, que se realicen de un modo o de otro o que no se realicen del todo es irrelevante para el derecho. Por el otro, su "regulación" jurídica puede dar origen a situaciones contradictorias, o bien, contraintuitivas. Del primer grupo forma parte la acción de caminar por las calles de una ciudad. En condiciones normales, por ejemplo, es irrelevante que las personas caminen por un lado de la calle o por el otro, cualquiera que sea la dirección en que marchen, y, por ello, el derecho no tiene necesidad de intervenir para regular esta acción humana, de modo que cada quien se regula de modo autónomo y se comporta como desea, sin que ello suscite mayores dificultades. Lo mismo sucede con la "actividad" de dormir, pues, a menos que se presente una situación de emergencia, el derecho deja en manos de las personas la decisión del momento de irse a la cama o de elegir la posición más adecuada para el propio organismo. Forman parte del segundo grupo situaciones que evidentemente el derecho no está en condiciones de regular sensatamente en modo alguno. Por ejemplo, tal vez resultaría extraño - cuando menos- que una disposición jurídica estableciera la obligación de ir al trabajo en taxi todos los lunes, o bien la prohibición de usar la corbata los días en que no se trabaja. Para el derecho, los eventos de los dos grupos son irrelevantes y omite cualquier referencia jurídica a ellos, y 
para muchos juristas esta omisión constituye un caso especial de regulación indirecta. ${ }^{9}$

En realidad, el caso del aborto no forma parte de ninguno de los dos grupos de acciones que el derecho regula sólo en forma indirecta. La valencia moral que lo rodea hace de él un acto social cuya regulación jurídica el derecho no puede omitir, si no se desea socavar una de las funciones fundamentales que han hecho posible el pacto social entre ciudadanos y Estado: garantizar la convivencia civil y pacífica. En ausencia de leyes al respecto, por ejemplo, quien practica abortos podría correr más riesgos que ahora, pues los que piensan que el aborto es un homicidio podrían considerarse autorizados a intervenir para tratar de evitar tales prácticas, aun mediante el uso de la violencia. ${ }^{10} \mathrm{El}$ aborto debe ser regulado jurídicamente en forma directa por los instrumentos del derecho; sobre ello no creo que puedan subsistir dudas. La cuestión problemática nace claramente en cuanto se considera el tipo de regulación que el ordenamiento jurídico debe producir en una determinada realidad, teniendo en cuenta, sobre todo, la consistente connotación moral que el aborto adquiere en la conciencia de las personas, y la profunda división entre las opiniones acerca de él.

La cuestión, como puede verse, no es nada fácil; por el contrario, es precisamente ahí donde se origina el debate acerca del aborto en todo el mundo, pues el modo como se regula deja siempre insatisfecha a una parte considerable de la población. Donde se permite el aborto legal, en ciertas condiciones, los movimientos pro-vida utilizan todos los medios a su alcance para que se introduzcan cambios en la legislación de manera que se prohíba; por otro lado, donde tal práctica constituye un delito, muchas personas combaten con denuedo con el fin de que se despenalice y que la mujer que desee abortar lo haga legalmente y en condiciones higiénicas y seguras.

En general, el modo directo de regular jurídicamente una materia puede a su vez dividirse en dos modalidades: una "fuerte" y una "blanda" (o "débil"). ${ }^{11}$ La primera de ellas, la modalidad fuerte, consiste en un tipo de intervención de los instrumentos jurídicos cuyo resultado es instituir obligaciones, deberes, derechos, sanciones, pues se establece tanto que una

9 Los juristas suelen referirse a tal modo "indirecto" como las normas de cierre de un sistema jurídico, es decir, como una estratagema mediante la cual se asegura la plenitud del sistema, evitando las lagunas. Un evento no considerado por el derecho se resuelve entonces considerándolo o bien excluido (todo lo que no está prohibido está permitido), o bien incluido (extendiendo la modalidad de regulación de un caso específico).

10 Y así sucede, a pesar de la existencia de una precisa regulación jurídica sustancialmente permisiva, en Estados Unidos.

11 "Fuerte" y "blanda" constituyen modalidades de intervención jurídicas que "conviven" en un ordenamiento jurídico, pues es del todo inimaginable un sistema jurídico completamente fuerte o completamente blando. 
cosa se debe (o no se debe) hacer, como la consecuencia jurídica que sigue a la conducta contraria. Se trata, evidentemente, de una intervención que refleja sin más una visión del derecho en su forma más tradicional, que se distingue por su carácter primario de tipo coercitivo. Uno de los representantes más preclaros de este modo de entender el derecho es sin duda Hans Kelsen, para quien, en efecto, ese carácter coercitivo del derecho hace - a manera de reflejo- que se considere norma primaria la que instituye el nexo entre la acción ilícita y la sanción correspondiente, mientras que la norma secundaria es, por el contrario, solamente aquella norma de carácter derivado cuyos destinatarios son los ciudadanos y que individualiza el comportamiento que sirve para evitar la sanción. ${ }^{12}$

Esta modalidad de intervención por parte del derecho regula el aborto calificándolo de modo más o menos preciso ${ }^{13}$ y estableciendo determinadas consecuencias. Ello es evidente si consideramos, por ejemplo, el caso mexicano, donde en el código penal vigente ${ }^{14}$ se define el aborto como la muerte del producto de la concepción en cualquier momento de la preñez, y se establecen sanciones jurídicas tanto para la mujer que se lo procure o consienta en que otra persona se lo haga, como para esta última. Como es evidente, la disposición jurídica general que resulta es el producto de la visión particular del Estado a través del legislador; la voluntad del legislador se personifica en la norma y se generaliza al mismo tiempo, convirtiéndose desde ese momento en voluntad general, en prescripción que vale para todos. De este modo se dispone que la voluntad de unos pocos, los legisladores nombrados por el sufragio popular, se convierta en la voluntad de muchos, y, además, que quienes no acaten las disposiciones establecidas reciban la reacción coactiva por parte de los órganos establecidos. A pesar de todo,

12 De Kelsen véanse al menos Reine Rechtslehre. Einleitung in die rechtswissenschaftliche Problematik, Franz Deuticke Verlag, Viena, 1934, y Reine Rechtslehre, Franz Deuticke Verlag, Viena, 1960. La distinción entre norma primaria y norma secundaria es en Kelsen, como se sabe, muy personal; para una visión diferente, vid. H.L.A. Hart, The Concept of Law, Oxford University Press, Londres, 1961, en especial los caps. I y II. Véase una exposición crítica en C.S. Nino, Introduzione all'analisi del diritto (1980), Giappichelli, Turín, 1996, especialmente el cap. II.

13 Se debe recordar que en virtud de muchos factores, que no es posible analizar detenidamente en este momento, la formulación de una disposición jurídica suscita casi invariablemente cuestiones de interpretación, es decir, el significado de los términos relevantes no se presenta casi nunca en forma precisa.

14 Para el Distrito Federal (DF) en materia de fuero común y para toda la República en materia de fuero federal. No examino las legislaciones estatales, teniendo en cuenta que, sustancialmente, no agregaría nada nuevo a las consideraciones que hago con respecto al DF. Además, conllevaría la necesidad de entrar en el detalle de cuestiones técnico-jurídicas, como la coherencia del orden jurídico y el control de constitucionalidad de las leyes, aspectos cuyo examen requiere una sede diferente. 
hay que decir que una situación análoga se configuraría si, en lugar de prohibir el aborto, éste se impusiera. La idea es menos peregrina de cuanto nos imaginemos: baste pensar en los severos métodos de control de la natalidad establecidos en China y la prohibición de tener más de un hijo. De cualquier modo, si pensamos que tales situaciones no nos conciernen directamente o las consideramos fruto de la imaginación, no podemos eximirnos de pensar que la intervención "fuerte" del derecho implica de suyo que la modalidad final de regulación puede ser de dos tipos: no sólo la prohibición de un comportamiento, sino también su contrario, la obligación de comportarse de un modo o de otro, que constituyen claramente las modalidades de intervención (y regulación) jurídica que caracterizan a un derecho "fuerte".

La segunda forma de intervención por parte de los instrumentos jurídicos se caracteriza, al contrario de lo que sucede con la forma "fuerte", por regular el mundo social de un modo particular que determina que podamos denominarla intervención "blanda". Un derecho, o un modelo de derecho, es "blando"15 no por calificar la realidad de modo indirecto, sino, más bien, por utilizar modalidades diferentes de las que utiliza un derecho "fuerte". Una de estas maneras es, sin duda, la que podemos configurar a partir de la consideración de la modalidad del permiso, es decir, de un modo de regular la realidad ya no prohibiendo determinados actos ni obligando a cumplir acciones, sino permitiendo que se realicen en condiciones particulares, establecidas jurídicamente. Se trata de una forma de intervención del derecho que responde a una visión diferente de la intervención "fuerte"; en aquel caso prevalece, a fin de cuentas, una concepción coercitiva del derecho, mientras que en éste de algún modo nos encontramos en presencia de una idea más amplia, abierta a una función del derecho que trasciende la mera reacción estatal en caso de violación de lo establecido.

\section{LA “TRAMPA” ANTIABORTISTA Y LA REACCIÓN DEL "ABORTISTA"}

La posición de quien ve con buenos ojos una legislación más liberal acerca del aborto (por ejemplo, que lo permita en los tres primeros meses del embarazo) es defendible plenamente, a mi parecer, a partir de observaciones meramente jurídicas, ${ }^{16} \sin$ "empantanarse" en cuestiones ético-filosóficas

15 O elástico, ligero, sobrio, abierto, útil, realizable, compatible. Sobre ello, véase el ensayo "Modelli di regolazione giuridica delle questioni bioetiche" de P. Borsellino, en id., Bioetica tra autonomia e diritto, Zadig, Milán, 1999.

16 A ellas se pueden sumar argumentos (o, mejor dicho, justificaciones) de orden sociológico y de políticas públicas; por ejemplo, subrayando las injusticias que se derivan de una legislación represiva en cuanto que las mujeres que lo pueden solventar recurren a personal médico bien capacitado, y las que no, se ven obligadas a dirigirse a comadronas o parteras de dudoso profesionalismo; también se puede evidenciar el alto costo social derivado del aborto 
cuyo resultado - en ausencia de un acuerdo preventivo sobre la definición de los términos clave- es la pura y simple contraposición. Siguiendo esta línea argumentativa, por ejemplo, el agudo trabajo de Margarita Valdés, "El problema del aborto: tres enfoques", corre el riesgo de ver minado el alcance teórico-práctico de los resultados que consigue. Ella, en efecto, llega a conclusiones del todo compatibles con una visión como la que aquí sostengo; pero lo hace al costo de permanecer circunscrita al terreno del debate que ha preparado a lo largo de los años la posición antiabortista, la cual, es conveniente recordarlo, en sus aspectos recientes nace a partir de la reacción a las legislaciones que a finales de los años sesenta y principios de los setenta —en Inglaterra y Estados Unidos, inicialmente- introdujeron elementos de mayor flexibilidad en la regulación del aborto, inaugurando de hecho la estación de los modelos "blandos".

En efecto, los diferentes grupos Pro-life y similares, que en Occidente combaten los modelos "blandos" o se baten por mantener un modelo "fuerte" en su versión prohibicionista, surgen como movimientos de reacción, y como tales no pueden hacer menos que fundar su propia posición en argumentos que tienen que ver con la adopción de premisas tales como: "la vida humana se inicia desde el momento mismo de la concepción", "desde la concepción el embrión es una persona", "la vida humana merece nuestro máximo respeto".

Pues bien, con el claro fin de sostener un posible cambio de la legislación mexicana con respecto al tema del aborto en una clave más abierta y permisiva, Margarita Valdés sostiene que - al menos durante el primer trimestre del embarazo - no existen razones para calificar de inmoral al aborto. ${ }^{17}$ A mi juicio, a pesar de su evidente intención —repito, que comparto plenamente-, Valdés no logra ir más allá del terreno de la discusión que tanto agrada a los antiabortistas, y que conduce casi necesariamente tanto a una estéril contraposición como al reforzamiento de los obstáculos conceptuales que impiden un debate más fructífero. ${ }^{18}$ En efecto, el intento de Valdés de justificar una legislación permisiva se concentra principal-

clandestino, ya que muchas mujeres se tienen que dirigir a estructuras sanitarias públicas para tratar de "remediar" los problemas provocados en ambientes antihigiénicos e inseguros.

17 Cfr. M. Valdés, op. cit., p. 149. La autora sostiene: "[en vista de que] el feto de, digamos, doce semanas, no es una persona en el sentido metafísico y moral de este término, y si [...] el feto antes de tener propiedades psicológicas no tiene un valor intrínseco propiamente moral, podemos concluir que el aborto en sí mismo no es un asunto moral cuando se lleva a cabo en los primeros meses de gestación. Si esto es correcto, no hay razones morales para prohibirlo legalmente." Las cursivas son de Margarita Valdés.

18 A mi parecer, lo mismo le sucede, cuando llega a las mismas conclusiones favorables a una legislación permisiva del aborto, a uno de los pioneros de la reflexión bioética en Italia en discusión acerca del aborto. Véase M. Mori, op. cit., p. 105. 
mente en el aspecto relativo a la moralidad (o inmoralidad) del aborto, sin explorar suficientemente el aspecto que está detrás de todo el debate: el universo jurídico de las prescripciones normativas. Cierto, Valdés enuncia claramente que su intento parte de una perspectiva de carácter exclusivamente filosófico-moral, de modo que son evidentes los instrumentos metodológicos de que se vale; sin embargo, no se debe olvidar que el debate acerca del aborto nace cuando aparecen las primeras legislaciones permisivas, ${ }^{19}$ lo que significa nada más y nada menos que la dimensión jurídico-social del problema es fundamental en el análisis, y que la pura instrumentación ético-filosófica corre el riesgo de no conducirnos a ningún lado si permanece encerrada en sí misma, sin conectarse con la cultura jurídica.

Como se decía antes, el principal argumento del antiabortista es más o menos el siguiente: si la vida humana se inicia con la concepción, y desde entonces el embrión es una persona ("uno de nosotros" es el eslogan preferido de algunos de ellos), se sigue que abortar equivale a asesinar y que asesinar es una acción inmoral. El argumento central para prohibir el aborto es fundamentalmente que el embrión es una persona. Entonces lo que trata de hacer Valdés es demostrar lo contrario: que el embrión no es una persona y que, en consecuencia, el aborto no es inmoral. ${ }^{20}$

¿Es el embrión una persona? Ciertamente el concepto de persona es uno de los más importantes en la cultura occidental, pues de algún modo termina repercutiendo en muchas de nuestras convicciones de los ámbitos filosófico, moral, político, social, jurídico. Se ha vertido mucha tinta al respecto sin que se haya podido llegar a un acuerdo más o menos compartido. No me es posible, entonces, ni siquiera mínimamente proponer aquí una reflexión definitiva y exhaustiva; en consecuencia, me referiré sólo al modo en que Valdés trata la cuestión, esperando que así el concepto de persona pueda adquirir algún sentido en la discusión sobre el problema específico del aborto.

Para ser sinceros, comparto la opinión de aquellos pensadores que piensan que colocar el aspecto moral en el centro de la reflexión sobre el aborto conduce a un callejón sin salida si se quiere dar una solución mediante el análisis de la idea de persona. ${ }^{21}$ La razón fundamental de esta "desconfian-

19 En efecto, antes de ello, los antiabortistas desperdigados aquí y allá por el mundo se encontraban satisfechos, pues la legislación concordaba grosso modo con su modo de ver las cosas.

20 Al prestar atención al desarrollo gradual del feto durante los nueve meses de embarazo, Valdés no ve problemas morales particulares durante los primeros meses; pero, acertadamente, enuncia algunas reservas en el caso de abortos tardíos. Cfr. M. Valdés, op. cit., pp. 149-150.

21 En este sentido opina J. Glover, Causing Death and Saving Lives, Penguin Books, Londres, 1977, también citado por Valdés (p. 131). 
za" de partir del concepto de persona es que el término es evidentemente ambiguo y pleno de implicaciones valorativas. Además, asumir una posición al respecto supone casi siempre el riesgo de colocarse en los linderos de la "pendiente resbaladiza". 22

A pesar de todo, para Margarita Valdés la discusión del concepto de persona para argumentar acerca de la (in)moralidad del aborto se puede justificar plenamente por dos razones: la primera, "porque aun cuando el concepto de persona sea un concepto valorativo, no es para nada obvio que no pueda tener criterios objetivos, públicos, de aplicación correcta y ser, por tanto, un concepto compartido", y la segunda, "porque la idea de que el feto es una persona es recurrente en los argumentos de quienes consideran que el aborto es una especie de homicidio y alguna respuesta tiene que dárseles". ${ }^{23}$ Luego pasa a examinar el concepto de persona y concluye de la manera como ya se ha apuntado, basándose fundamentalmente en la perspectiva de la "metafísica descriptiva" desarrollada por Peter Strawson. ${ }^{24}$ Antes de analizar la manera en que Valdés procede, creo que puede ser conveniente detenerse un poco a considerar las razones que según ella justifican su punto de partida.

Para comenzar, sin duda Valdés no ignora la enorme complejidad que encierra el concepto de persona, y que lo convierte en una noción cargada de implicaciones valorativas; sin embargo, para ella esto no determina necesariamente que no se lo pueda analizar para llegar a conclusiones de carácter compartido y a su aplicación correcta, mediante el uso de criterios objetivos. A mí me parece, con toda sinceridad, que la argumentación de Valdés no es del todo convincente y que, por el contrario, contiene más de una contradicción que pone en entredicho su alcance teórico. Si la noción es valorativa, ¿cuáles serán sus criterios objetivos? ¿Cómo tendrá que ser su aplicación (o su uso) lingüística(o) para que se pueda considerar co-

22 El argumento retórico denominado slippery slope goza de mucha atención en la literatura filosófica moderna, sobre todo en el terreno de la ética práctica. En concreto, el argumento consiste, como se sabe, en hacer patentes las consecuencias - frecuentemente indeseadas, si no es que hasta contraintuitivas- que se siguen una vez que se ha aceptado una determinada premisa y/o una determinada postura. Es paradigmático al respecto el caso de la eutanasia: se argumenta, por ejemplo, que una vez que se permite a un hombre "asesinar" a otro según su propio discernimiento, no hay manera de precisar un límite, una base racional mediante la cual se pueda evitar que el límite pueda desplazarse cada vez más adelante. Sobre el slippery slope argument, véase S. Castignone, "Quanto si scivola sulla china? Nuove fortune nel vecchio sorite", en AA.VV., Studi in memoria di Giovanni Tarello, Giuffrè, Milán, 1990, vol. II, pp. 111120, reimpreso en S. Castignone, Nuovi diritti e nuovi soggetti. Appunti di bioetica e biodiritto, ECIG, Génova, 1996, pp. 219-228.

23 M. Valdés, op. cit., p. 131.

24 Cfr. P. Strawson, Individuals. An Essay in Descriptive Methaphysics, Methuen, Londres, 1959. 
rrecta(o)? ¿O acaso el calificativo 'valorativo' posee una área de significado donde no cabe ninguna consideración que tenga que ver con vocablos como 'objetivo', 'correcto', 'verdadero'?

Reconocer, como lo hace Valdés, la carga valorativa del concepto de persona y, no obstante, suponer que para su estudio existen de cualquier modo criterios objetivos, correctos, podría conducir a algunas dificultades. Existe, a mi parecer, una vía para salir del embrollo; pero no creo que sea interesante para los fines que Valdés se impone. Está claro que la posible investigación sobre la idea de persona tiene como resultado un conjunto de enunciados mediante los cuales se comunican las tesis a que se llegue; tales enunciados pueden ser, por un lado, de naturaleza descriptiva, si el resultado es la simple "información" de la idea de persona sostenida por un determinado pensador y/o que esté presente en un determinado contexto, o bien, por el otro, pueden ser de una naturaleza que podemos llamar normativa si, por el contrario, se superan los límites de la mera información para expresar las propias tesis al respecto. Sólo en el primer caso el enunciado acerca del concepto de persona supera la esfera valorativa, pues ofrece criterios de objetividad para juzgar de la verdad o la falsedad, según que el enunciado corresponda a la realidad o no; pero no creo que éste sea el sentido de la tesis que sostiene Valdés, quien no se limita a informarnos acerca de la existencia de las tesis de Strawson: su tesis, si no me equivoco, puede más bien adscribirse al universo de la normatividad, a la prescripción más que a la mera información. Pero si es así, entonces, al conjunto de enunciados que la componen le resulta impropio el juicio de verofuncionalidad: en efecto, es más adecuado referirnos a tales enunciados en cuanto a su "conveniencia" y alcance explicativo.

Sin embargo, como diré más adelante (§ VIII), personalmente no excluyo que de la no verofuncionalidad del concepto de persona, contra todo lo que se podría pensar, se derive de manera necesaria la imposibilidad de su discusión racional, tanto en el nivel filosófico general como en el caso específico del aborto.

Por otro lado, Valdés justifica el análisis del concepto de persona argumentando que, dado que los antiabortistas lo utilizan como base de sus tesis, se hace necesario examinarlo. Ella tiene razón en parte: algunos de los más destacados componentes de la corriente antiabortista hacen del concepto de persona su caballo de batalla, manteniendo así el debate exclusivamente en el terreno metafísico y filosófico, acusando además a los abortistas de sustraerse a la discusión. ${ }^{25}$ Sin embargo, a mí me parece que se comete un

25 Véase, a título de ejemplo, la posición sostenida por F. D’Agostino, profesor de Filosofía del Derecho en la Universidad de Roma "La Sapienza", ex presidente del Comité Nacional de Bioética y uno de los más aguerridos combatientes contra la ley italiana (No. 194, 22 de mayo 
error no carente de consecuencias cuando a la provocación antiabortista se responde dedicándose a un examen del concepto de persona, pensando que la forma más viable de justificar el aborto es combatir con las armas de la ética, para establecer si el aborto es o no moralmente correcto. Lo máximo, tal vez, que un abortista podría conceder a los adversarios es aceptar la "lucha" en el campo del concepto de persona para mostrar las posibles incoherencias (y existen, ivaya si existen!) de la posición antiabortista, eventualmente valiéndose de los instrumentos que la semiótica pone a nuestra disposición, pero sin caer en la "trampa" que consiste en oponer a una definición realista otra definición realista, o sea una definición que presupone la correspondencia (o no correspondencia) de un término con la "cosa" en sí. Además, dice Valdés, es necesario dar una respuesta a quienes afirman que el aborto es un homicidio. La respuesta, a mi juicio muy sencilla, es que 'homicidio' es un vocablo técnico-jurídico, y en cuanto tal designa un evento del mundo empírico calificándolo. En otras palabras, no existen homicidios como cosas en sí de la naturaleza (existe el hecho empírico de alguien que apuñala o le dispara a otro), sino solamente eventos que el derecho califica de homicidios.

\section{V. ¿ES EL EMBRIÓN UNA PERSONA?}

En su tentativa de "demostrar" que el embrión es una persona, los antiabortistas se valen de consideraciones acerca del inicio de la vida, como ya se ha dicho antes. Para ellos, la vida se inicia desde el momento mismo en que el espermatozoide se une con el óvulo. Si la vida humana se inicia en ese momento y no existe ninguna razón sustancial para reconocer diferencias entre esa forma de vida y la vida de un humano adulto, se sigue necesariamente que ambas manifestaciones merecen nuestro máximo respeto, $\mathrm{y}$, en consecuencia, el aborto se configura como una acción moralmente reprobable. Margarita Valdés está en desacuerdo con pensadores que, como Singer, Tooley y Warren, justifican el aborto a partir de una idea de persona que toma como paradigma seres humanos racionales y conscientes; ${ }^{26}$ para ella, de alguna manera esta tesis — con la que de cualquier manera

de 1978) que en la práctica autoriza a la mujer a abortar libremente hasta los tres meses de embarazo; cfr. F. D’Agostino, "La legislazione italiana e la difesa della vita", en Bioetica nella prospettiva della filosofia del diritto, 2a. ed., Giappichelli, Turín, 1997, pp. 269-272. Véase, en el mismo libro, el ensayo "I diritti del nascituro", pp. 281-286.

26 "Humanos adultos en pleno uso de sus facultades", según las palabras de Valdés (op. cit., p. 134). Cfr. P. Singer, Practical Ethics, 2a. ed., Cambridge University Press, Cambridge, 1993; M. Tooley, Abortion and Infanticide, Oxford University Press, Oxford, 1983; M.A. Warren, "On the Moral and Legal Status of Abortion", Monist, 57, 1973. Yo agregaría entre ellos a H.T. Engelhardt Jr., The Foundations of Bioethics, Oxford University Press, Oxford-Nueva York, 1986. 
comparte el resultado último- comporta el riesgo de caer en la "pendiente resbaladiza" de tener que excluir de la clase de las personas no sólo a los embriones, sino también a los infantes, a los retardados mentales, a quienes yacen en un estado vegetativo permanente como consecuencia de un evento traumático. En efecto, como es sabido, el utilitarismo de la preferencia de Peter Singer se ve obligado, como consecuencia de su tesis de fondo, a conceder argumentos en favor del infanticidio. ${ }^{27}$ Por esta razón, Valdés abandona esta línea de acción de indagar sobre la idea de persona dentro de la metafísica "tradicional", para abrazar las tesis de Peter Strawson que, a su juicio, resultan más iluminadoras. En lo que se ha dado en llamar una "metafísica descriptiva", Strawson sustancialmente sostiene que a la respuesta de cuáles son las notas distintivas del concepto de persona se debe recurrir a la idea de persona como particular básico, a la que se le pueden atribuir tanto propiedades corporales como estados de conciencia. En la opinión de Valdés, tal caracterización

captura una intuición fundamental: no reconoceríamos como una persona (en el sentido normal de esta palabra) a algo puramente material que no tuviera o no fuera capaz de tener ninguna propiedad psicológica o que careciera de la habilidad para llevar a cabo cualquier acción intencional. Si algo tiene sólo propiedades materiales, digamos, una piedra o un helecho, no podremos ver a ese algo como una persona, no sería adecuado tener con él el tipo de consideraciones que normalmente tenemos frente a las personas. ${ }^{28}$

Siguiendo a Strawson, ella afirma entonces que responder a la pregunta de si un feto es una persona "presupone contestar a la cuestión de si se le pueden atribuir con verdad predicados psicológicos, por simples que éstos puedan ser". ${ }^{29}$ De lo que se sigue, por supuesto, que la respuesta acerca de las entidades que debemos considerar como personas puede ser diferente en razón de los distintos estadios por los que pasa un óvulo desde el momento de su fecundación hasta el nacimiento: un óvulo apenas fecundado no será una persona, ni tampoco un feto de dos meses; pero sí lo será un feto de seis meses en cuanto que de él se puede afirmar con verosimilitud que es capaz de experimentar frío, dolor, hambre o incomodidad. De manera que, entonces, el aborto para Valdés puede justificarse moralmente en las primeras doce semanas del embarazo, ya que se relaciona con "algo" a lo que no es posible considerar como persona, mientras que en los estadios sucesivos de desarrollo ella está dispuesta a reconocer que la cuestión se

27 Véase P. Singer, op. cit., cap. VI.

28 M. Valdés, op. cit., pp. 134-135.

29 Ibid., p. 135. 
hace más complicada y que merece mayor atención de parte de las personas con conocimientos científicos específicos de la materia.

Si la discusión acerca del concepto de persona tiene algún sentido, éste ha de ser el de la búsqueda de significado de 'persona', y la teoría moderna de las definiciones — dentro del campo más amplio de la semiótica- nos pone en alerta respecto de una teoría esencial-realista que supone que las definiciones versan sobre cosas y no sobre palabras. Como es sabido, en la teoría realista de la definición — que encuentra sus raíces en el pensamiento aristotélico-platónico—, una definición puede ser verdadera o falsa, según que el definiens contenga o no las características esenciales del definiendum. Ahora bien, a mi juicio, Margarita Valdés no pone suficiente atención en las implicaciones - tanto de orden teórico como de naturaleza práctica- que supone su operación intelectual, pues el sentido de su investigación consiste, precisamente, en oponerse - moviéndose dentro de la teoría de la definición - a una visión realista (y esencialista) con otra visión realista. De ese modo, creo, no se manifiesta satisfactoriamente el sentido final de la disputa, que consiste en la adhesión a un modelo de regulación jurídica (o en la crítica de él) que toma en cuenta un aspecto de la vida social. Además, no se muestra otra importante función de la teoría moderna de la definición: la definición nominal (en sus variantes estipulativa y explicativa), y se olvida completamente de una característica funcional fundamental en el uso del lenguaje como instrumento de comunicación, a saber, su valencia nominalista, convencional.

Valdés luego sostiene que el feto (en su estadio de desarrollo inicial) no es una persona, para, de esa manera, oponerse a los antiabortistas que sostienen justamente lo contrario. Es evidente, por tanto, que no se trata de una mera controversia lingüística acerca del significado de una expresión. En efecto, el sentido de las operaciones tanto de la una como de los otros no es, aparentemente, una pura operación re-cognitiva, que tiende a una simple recopilación del uso que una determinada comunidad de hablantes hace de la expresión objeto de la disputa. Si así fuese, el desacuerdo entre ellos se colocaría dentro de los márgenes de una definición lexical, y se podría fácilmente ver quién tiene la razón verificando la correspondencia de sus afirmaciones con la realidad fáctica; con ello la disputa verbal llegaría a su fin. Lo que tratan de hacer, si no me equivoco, es superar la mera definición lexical para proponer la "verdadera" definición.

Valdés trata de determinar "la noción de persona verdaderamente relevante para el debate acerca de la moralidad del aborto". ${ }^{30}$ ¿Cuál es el significado de 'verdaderamente' en la cita anterior? Me parece, si bien corro el riesgo de equivocarme, que bajo ese término subyace una idea de definición como

30 M. Valdés, op. cit., p. 133, el subrayado es mío. 
la actividad capaz de establecer el "verdadero" significado, es decir, la tesis de que definir consiste en la búsqueda de la "esencia" mencionada en el definiens, que una definición es o verdadera o falsa según corresponda o no a tal esencia.

Ahora bien, como ya decía antes, es una opinión bastante difundida entre los estudiosos del lenguaje que las únicas definiciones que pueden ser verdaderas (o falsas) son las definiciones lexicales —o léxicas-, es decir, las que describen un uso lingüístico determinado en una comunidad determinada. El realismo definitorio, cuyas raíces se prolongan hasta el pensamiento platónico, ha sido fuertemente criticado por la teoría moderna de la definición, por Carnap y la tradición que en él se inspira. La razón de la crítica es evidente: ¿existen las esencias verdaderas de las cosas? ¿Puede el intelecto humano conocerlas? ¿Existe en alguna parte la belleza en sí, de la que participan los entes que consideramos bellos? Regresando a nuestro tema: ¿cómo podemos estar seguros de que nuestro concepto de persona es el verdadero? ¿De qué manera respondemos a quien sostiene que el verdadero concepto de persona incluye los óvulos apenas fecundados? ¿En qué momento preciso se inicia la vida humana? Una vez que hemos llegado a este punto de la discusión, parece que es determinante dar una respuesta a esta última interrogante. Y si consideramos la breve historia de la bioética, al menos en lo relativo al ámbito particular del aborto, de la experimentación genética y de la procreación asistida, encontraremos que el tipo de respuesta a la que se llegue tendrá enormes implicaciones tanto para la reflexión teórica como para la investigación científica.

\section{EL INICIO DE LA VIDA HUMANA}

En 1982 fue instituida en Inglaterra —en respuesta a las interrogantes y a las preocupaciones nacidas en relación con las nuevas técnicas de fecundación artificial humana - una comisión gobernamental conocida con el nombre de Comité Warnock, por el apellido de su presidente, la profesora de filosofía del Girton College de Cambridge, Mary Warnock. Con tal comisión se trataba de dar una respuesta a la preocupación sobre la suerte de los embriones durante los procedimientos de fecundación in vitro, y, de modo particular, de dar una respuesta relativa a su estatus. En el documento aprobado por la comisión, y presentado al Parlamento en 1984 (Report of the Committee of Inquiry into Human Fertilization and Embriology, conocido como Informe Warnock), se recomienda la prohibición de utilizar, con fines experimentales, embriones que hayan superado el decimocuarto día de desarrollo, aun estableciendo que: 
si bien las preguntas relativas a cuándo se inicia la vida o la persona puedan ser de hecho susceptibles de respuestas directas, consideramos que tales respuestas son una amalgama compleja de juicios factuales y morales. Por ello, en lugar en tratar de responder a estas preguntas, nos trasladamos directamente a la cuestión de cómo puede ser justo tratar al embrión humano. Hemos examinado qué estatus se debería adjudicar al embrión humano. ${ }^{31}$

El Comité nos subraya un aspecto de crucial importancia: el hecho de que a la pregunta acerca del inicio de la vida se pueda responder involucrando factores tanto de hecho como de valor, juicios factuales y morales. En efecto, también en la declaración de disenso de tres miembros del Comité respecto del informe en sus términos generales, podemos notar esta sensación:

¿Cuándo es que la persona humana comienza a existir? Tampoco aquí se puede dar una respuesta simple. El inicio de la vida de una persona no es una cuestión de hecho, sino una decisión que se toma a la luz de principios morales. El problema debe reformularse de este modo: ¿en qué estadio de desarrollo debería concederse la condición de persona a un embrión humano? Las personas responden a estas preguntas de manera diferente. Algunos señalan la fecundación; otros, el anidamiento; otros más, un estadio de desarrollo más tardío. La observación científica y la reflexión filosófica y teológica pueden esclarecer la pregunta, pero no proporcionar la respuesta. ${ }^{32}$

A pesar de todas estas dificultades que no se resuelven con la simple observación, el Comité se pronuncia en términos bastante definitivos: recomienda que se adopten leyes que prohíban la experimentación con los embriones una vez que éstos hayan superado el decimocuarto día a partir de la fecundación. El Informe Warnock, hay que notarlo, no toma explícitamente partido en la diatriba acerca del inicio de la vida humana, pues recomendando el decimocuarto día como término máximo para la experimentación, adopta claramente un determinado punto de vista, detrás del cual están ciertas razones de tipo moral junto con argumentos científicos. El argumento científico que en parte parece liberar esta tesis de la sospecha de arbitrariedad es que el decimoquinto día después de la fecundación se verifica la formación de la estría (o franja) primitiva que a su vez determina el inicio del desarrollo individual del embrión. Este momento constituye, en efecto, un hito: hasta antes de la formación de tal estría existe siempre la posibilidad de que el embrión se divida dando lugar a la formación de gemelos idénticos, mientras que, una vez formada, el desarrollo previsible

31 Cito traduciendo la versión en italiano. Rapporto Warnock, Quali frontiere per la vita?, Avvenire, Cernusco sul Naviglio, 1985, 11.9, p. 88.

32 Ibid., p. 118. 
es solamente la formación y el nacimiento de un ser humano único. Con la formación de la estría cesa la totipotencialidad de las células.

Estudios de embriología demuestran sin posibilidad de duda que a partir de la primera segmentación de la célula fecundada, es decir, en el estadio de dos células idénticas de dimensiones casi iguales, está presente la posibilidad de que el proceso dé origen a gemelos monocigóticos, cuyas características cambian en razón del estadio en el que se verifica la segmentación. La posibilidad de segmentación —que ya después del decimotercer día origina gemelos siameses, es decir, no completamente separados- viene a cesar hasta el decimoquinto día, y para muchos - comprensiblemente también para la mayor parte de los miembros del Comité Warnock- es entonces cuando se puede decir con propiedad que ha dado inicio una vida humana individual y única. Hasta antes del anidamiento, y más claramente antes de que el número de subdivisiones celulares supere las ocho unidades, cada una de éstas toma por sí misma las sustancias necesarias para su nutrición, demostrando así su propia autonomía vital. Y también para Norman M. Ford, "esta circunstancia parece indicar que todo blastómero, ${ }^{33}$ al menos hasta el estadio de ocho células, es un individuo ontológico viviente distinto, aunque el lapso de vida de cada blastómero no alcance las 24 horas". ${ }^{34}$ Resulta muy difícil, en efecto, considerar como ser humano un conglomerado indistinto de células, cuando cada una de ellas podría, en teoría, dar lugar a un ser humano.

A partir del decimoquinto día se puede hablar propiamente -o sea, con cierta verosimilitud - de individuo en sentido ontológico. ¿Se desprende de ello que antes de este momento no se pueda hablar de persona humana? Para algunos la respuesta es afirmativa, aunque permanece la duda de que el concepto denotado por 'persona humana' sea más bien una creación jurídico-filosófica y no, como se pretende, observacional, factual, que se pueda desprender de la mera observación empírica.

Para llegar a esta conclusión existen otros argumentos no menos importantes, de algún modo relacionados con el anterior. Uno de ellos concierne al proceso de anidamiento del embrión en el útero, donde, si el curso de las cosas procede de modo regular, proseguirá su desarrollo hasta la fase en que se dé a luz a un nuevo ser. El anidamiento se verifica aproximadamente entre el sexto y el decimotercer día después de la fecundación. Tal proceso constituye uno de los pasajes determinantes del desarrollo completo del embrión; en efecto, una vez que el anidamiento ha sido completado, aumenta en modo significativo el porcentaje de posibilidades de que el proceso de

33 Célula embrional primitiva derivada del óvulo fecundado.

34 Cfr. N.M. Ford, op. cit., p. 208. 
gestación se concluya con el nacimiento de un nuevo ser. Antes de este momento, existe una especie de "barrera" colocada por el mismo curso natural de los eventos que a veces impide el anidamiento de óvulos fecundados; de hecho, se calcula que menos de un tercio de los óvulos fecundados superan con éxito las fases preliminares, desde el momento del encuentro con el espermatozoide en las trompas de Falopio hasta su llegada a la cavidad del útero, en que termina adhiriéndose a la pared de éste y donde podrá satisfacer sus necesidades de nutrición. ${ }^{35}$ Otro argumento concierne al hecho de que hasta el estadio conocido como blastocito, el embrión humano está formado por células cuyo destino final en la conformación del nuevo ser y en el medio de su nutrición no está determinado. En otras palabras, es sólo después de que se ha superado el número de 64 células, cuando de la fase de la mórula se pasa al estadio del blastocito, que en el embrión se distinguen cuáles serán las células que formarán al embrión propiamente dicho y cuáles formarán la placenta, por ejemplo. Ello hace que sea aún más difícil considerar el embrión como un ser humano en una fase precedente a esta diferenciación. Mary Warnock, presidente del Comité que lleva su nombre y que recomendó que las investigaciones acerca del embrión terminasen el decimocuarto día, afirma al respecto en un escrito posterior:

La mayor parte del Comité recomienda que la investigación sobre el embrión humano termine con el decimocuarto día, es decir, en el momento en que se forma la estría primitiva. Hasta este momento es difícil pensar que el embrión sea un individuo, ya que podría dar lugar a dos individuos. En este estadio inicial, el embrión no satisface ninguno de los criterios de identidad que se aplican a mí, a Tom, a Dick o a Harry, y que distinguen a cada uno de nosotros de los demás. Y, además, un conjunto de células, si bien más o menos identificadas, no pueden aún constituir verdaderamente ni una cosa ni las otras. La situación está todavía incierta. Pero a partir del decimocuarto o decimoquinto día en adelante ya no hay dudas: se desarrolla o Tom o Dick o Harry, o quizá los tres, pero como seres individuales. En este estadio, entonces, el embrión ya se ha diferenciado de las células que en el útero formarán una membrana protectora o la placenta. ${ }^{36}$

35 Patricia Jacobs sostiene que el 30\% de los embarazos detectados mediante la reacción positiva al test de la gonadotropina coriónica humana (HCG) terminan en un aborto espontáneo antes de ser clínicamente verificados. Cfr. Pregnacy Losses and Birth Defects, en C.R. Austin y R.V. Short (comps.), Embryonic and Fetal Development, libro II, Reproduction in Mammals, Cambridge University Press, Cambridge, 1982, pp. 146-147. También A.J. Wilcox et al., Incidence of Early Loss of Pregnacy, "New England Journal of Medicine", 1988, 319, pp. 189-194.

36 Cfr. M. Warnock, "Do Human Cells Have Rights?", Bioethics, 1, 1987, pp. 11-12. 
Esta digresión (aparentemente) larga, centrada en el análisis de los resultados a que llega el Comité Warnock, nos puede aclarar mejor la percepción del problema. Para comenzar, está claro que la pregunta acerca del inicio de la vida implica dar una respuesta a cuestiones que no se limitan al terreno meramente factual sino que se colocan también en los terrenos filosófico y moral. Aun en presencia de determinados datos científicos, como los que toma en consideración el Comité, la respuesta parece no ser sencilla: por ejemplo, se debe recordar que algunos responden a la pregunta sobre el inicio de la vida indicando el momento en que el feto es viable, es decir, cuando es capaz de sobrevivir fuera del cuerpo de la madre. ${ }^{37} \mathrm{Y}$ también se deben tomar en consideración — para evidenciar aún más la complejidad de la pregunta- las posiciones de pensadores como Singer, Tooley y Warren, quienes de algún modo parecen responder a la pregunta en cuestión con palabras que podrían parecen aún más "escandalosas": con un implícito paralelismo entre la idea de persona y el inicio de la vida se podría pensar que ellos colocan el inicio de la vida en un momento posterior al mismo nacimiento, cuando ya existen la autoconciencia y la razón.

\section{ARGUMENTOS JURÍDICOS EN UNA CUESTIÓN MORAL}

Cuán compleja resulta la pregunta acerca del inicio de la vida humana se muestra suficientemente, a mi juicio, tanto por las conclusiones como por los argumentos utilizados por el Comité Warnock. En su informe, repito, se recomienda fuertemente la formulación de disposiciones jurídicas que prohíban la experimentación con embriones que hayan superado el decimocuarto día, y también se sostiene que, en todo caso, ello no constituye una respuesta a la pregunta en cuestión, en razón de que ésta implicaría una respuesta donde se mezclan tesis factuales con elementos de orden moral. Así pues, podemos ver fácilmente que el Comité Warnock no proporciona ningún argumento en favor de las tesis contendientes acerca del aborto. De hecho, podemos inferir, hasta el decimocuarto día de "vida" del embrión el Comité no se opone al aborto; pero, por otro lado, quince días son sólo quince días, y no doce semanas o más, de manera que, superado ese límite, la cuestión se hace más espinosa y controvertida.

Ahora queda claro, pienso, que este sendero de indagaciones no conduce a ningún lado. Al seguirlo, lo único que se obtiene es desvelar el principio moral que está detrás de las posiciones en conflicto como razón última justificatoria, la cual, no siendo compartida por todos contiene irremediablemente el germen de la contraposición: desemboca en un nivel del debate

37 Otra tesis, aunque hoy en día está casi del todo abandonada, coloca el inicio de la vida en el momento en que el feto se mueve (o más bien, cuando la madre puede percibir su movimiento). 
en el que un principio último se opone a otro principio último, sin posibilidad de superar el conflicto de manera racional.

Es entonces cuando entran en juego - y pueden resultar decisivosargumentos como el que aquí he tratado de formular, es decir, la consideración del problema del aborto a partir de aspectos que tengan que ver con el universo jurídico-normativo, con el conjunto de disposiciones y de acciones mediante las cuales el Estado regula la vida social. Retomemos la reflexión ya iniciada acerca de los modelos de regulación social jurídica.

La alternativa entre modelo "fuerte" y modelo "blando" de regulación jurídica surge también - y tal vez con mayor evidencia- en casos como el que constituye el núcleo de este trabajo. A diferencia del modelo "fuerte", el modelo "blando" se configura como una modalidad de calificación jurídica donde la voluntad del legislador prevalece sobre la voluntad general de manera bastante limitada. Prevalece, en otras palabras, sólo en cuanto órgano encargado de emanar en forma específica las disposiciones jurídicas relativas al caso; pero no prevalece, y esto es significativo, imponiendo coercitivamente su voluntad (si se puede hablar de voluntad del legislador) particular. El aborto, en una perspectiva de este tipo, no se considera ni como prohibido ni mucho menos como obligatorio, sino solamente como permitido en determinadas circunstancias. De esta manera, el modelo asegura que la voluntad de unos pocos no interfiera en la voluntad de muchos, que algunos principios morales individuales se conviertan en modelo de conducta válido para la generalidad. El principio regulador que está en el centro del modelo no es, pues, la coacción ni un subrepticio principio moralístico-paternalista, sino el principio de la independencia del juicio moral individual y de la responsabilización. En este modelo, el derecho no prohíbe a nadie abortar, ni mucho menos lo obliga a hacerlo; determina simplemente las condiciones en las cuales quien lo desea puede hacerlo sin incurrir en sanciones jurídicas.

En los países donde aún se considera el aborto como un delito prevalece, como es fácil notar, un modelo de regulación "fuerte". En estas legislaciones, como en el caso de México, se determina la conducta ilícita conectándola con la sanción estatal: se trata ni más ni menos que de una prohibición. En otros términos, hay una connotación moral específica del aborto establecida por la conciencia de unos (pocos) y que se extiende a todos sin miramientos, prescindiendo de cualquier otra consideración de carácter individual. Por otro lado, en los países donde existe una legislación más permisiva es evidente que nos encontramos frente a un modelo "blando" de regulación jurídica, con modalidades específicas que cambian de país en país, dependiendo, en todo caso, de los factores particulares que fungen como condición sine qua non. 
La posición sostenida por Margarita Valdés en el artículo ya citado es compatible en buena medida con el modelo "blando" de regulación. Sin embargo, lo que no es compatible con las reflexiones expresadas en este trabajo es su base argumentativa, pues, en mi opinión, consiste en un juicio subjetivo con pretensiones de universalidad, y contribuye a hacer aún más rígidas las tesis contrapuestas. Me explicaré con otras palabras. Tomar como punto de partida la noción de persona, o bien el concepto de inicio de la vida humana (o ambos, puesto que están estrechamente relacionados), produce resultados más bien estériles. Ni una ni otra tesis, a partir de tales consideraciones, logra convencer racionalmente a ninguna persona que se reconozca en la tesis opuesta, ya que, como se ha subrayado, a final de cuentas la argumentación conducida de ese modo no puede superar el obstáculo representado por el principio último de las tesis: cada quien se "enroca" detrás de su propio principio moral último una vez que no le es posible justificarlo con base en otro superior. Finalmente, esta forma de argumentar favorece únicamente el reforzamiento de las tesis para quien ya se reconoce a priori en ellas, pero sin lograr suscitar dudas en quienes adoptan las tesis opuestas.

Por el contrario, abandonando este terreno, es decir, valiéndose no tanto de argumentos morales, sino de consideraciones de orden jurídico, quizá la discusión pueda resultar más fructífera. A mi juicio, el aborto no es menos moral o inmoral según que se realice en una fase temprana o tardía del desarrollo del embrión. Si de alguna manera se me obligara a pronunciarme en este sentido, con toda sinceridad yo no podría hacer otra cosa que declarar mi juicio moral negativo, aunque subrayando que mi posición es del todo individual y, además, haciendo evidente que, en todo caso, se trata de una convicción estrictamente deontológica, mientras que en el terreno teleológico yo no estaría jamás en condiciones de enjuiciar negativamente a una persona que tenga una opinión diferente. Aún más, mi posición deontológica ni siquiera me pone a salvo de un posible replanteamiento; el mundo deontológico, es decir, el mundo como debería ser, en muchas ocasiones difiere completamente de la manera en que las circunstancias concretas van orientando una conducta real, a veces en una dirección diferente de la propia convicción moral. ${ }^{38}$ En otras palabras, se trataría de una posición

38 Sobre este argumento de la no contradicción entre una perspectiva deontológico-moral contraria al aborto y una posible conducta teleológico-jurídica que lo permita en ciertas condiciones, son siempre insuperables las reflexiones de Uberto Scarpelli; véase de él mismo "La bioetica. Alla ricerca dei principi", en Biblioteca della libertà, XXII, 89, 1987, pp. 7-32, reimpreso en Bioetica laica, Baldini e Castoldi, Milán, 1998, pp. 217-247, en especial las pp. 244-247. Bioetica laica, publicada póstumamente, es una recopilación de diversos escritos menores de Scarpelli (1924-1993), quien en el campo bioético sostenía, a mi juicio, verdaderamente una postura laica, o sea una postura que no es absolutamente antirreligiosa. En su tesis laica, 
que, a partir de un imperativo categórico de matriz kantiana, no impide en modo alguno que un modelo de conducta pueda también — como de hecho sucede- ser matizado en determinadas circunstancias con consideraciones de tipo prudencial, atento al cálculo de las consecuencias de la acción.

Un modelo de regulación "blando" para el aborto sugiere, entonces, una legislación en la que el legislador no se comprometa con una de las dos visiones contrapuestas, pues de hacerlo no solamente dejará insatisfecha a una parte de los ciudadanos, sino que también objetivará en el derecho una idea acerca de la cual no hay acuerdo moral. Tanto las posiciones de los abortistas como las de los antiabortistas son, en este orden de ideas, posturas deontológicas, en las que existe un presupuesto moral; y ni a una ni a otra se puede responder eficazmente con su contrario si se desea realmente una recomposición del conflicto. Esta recomposición, que no es posible establecer en ese terreno, sí puede serlo en el terreno teleológico y jurídico, es decir, considerando los fines que se persiguen con la legislación y los medios para alcanzarlos: por ejemplo, considerando que el aborto clandestino es un precio demasiado alto que una legislación represiva hace pagar a la colectividad.

En muchas partes del mundo, la experiencia demuestra suficientemente que una legislación que prohíba el aborto (en una de las alternativas del modelo "fuerte") no impide que muchas mujeres recurran al aborto. Al mal que representa el aborto se vienen así a sumar otros males: el horror de la clandestinidad y de la inseguridad, y la injusticia por el hecho de que algunas mujeres abortan en condiciones mejores que otras solamente en virtud de la propia disponibilidad de medios materiales. Si el legislador adoptase en nuestro país una regulación que permitiera el aborto en ciertas condiciones, no influiría mayormente, al menos a corto plazo, en el número total de abortos que hoy en día se practican. A mi juicio, en efecto, teniendo cada uno de nosotros una idea más o menos bien configurada sobre el aborto, resulta bastante difícil pensar que quien moralmente se siente contrario al aborto se convencerá de abortar porque la ley se lo permite. Si lo hace, probablemente la razón última residirá en el hecho de que con esa ley o sin esa ley esa persona igualmente lo habría hecho, precisamente por el balance implícito que todos realizamos en situaciones decisionales, críticas, entre razones conectadas con la moral kantiana (deontológico-moral) y razones

Scarpelli no piensa que el universo moral entero sería el mismo tanto si Dios existiera (Deus est) como si no existiera (etsi Deus non daretur). Él no niega la relevancia moral de Dios; al contrario, sostiene que si existiera el Dios de los cristianos y nosotros pudiésemos conocerlo, la bioética y todo nuestro universo moral resultarían condicionados. Sin embargo, agrega, no pudiendo conocerlo, nos descubrimos como seres humanos obligados a "localizar" por nuestra cuenta y con nuestras fuerzas los principios que guíen nuestras acciones. De Scarpelli véase también "Bioetica: prospettive e principi fondamentali", en Bioetica laica, pp. 37-56. 
que tienen que ver con motivos teleológicos de realización concreta, donde el mundo abstracto se confronta con las consecuencias tangibles de nuestras acciones.

Cierto, es posible que la idea de un modelo "blando" de regulación del aborto resulte inadmisible para quienes - a pesar de cuanto se ha dicho en relación con el inicio de la vida y la idea de persona- están convencidos de que el aborto es un homicidio. A ellos se les puede objetar que el modelo en cuestión no comporta un juicio ni moral ni jurídico sobre el aborto: en otras palabras, no se afirma que el aborto no sea un homicidio. De lo que se trata, en todo caso, es de valorar de modo crítico las condiciones en que se encuentra la mujer que desea abortar y las consecuencias de una u otra alternativa que tome, $\mathrm{y}$, a final de cuentas, decidir en manos de quién debe caer la decisión de hacerlo o no hacerlo: ¿en la mujer?, ¿en la sociedad? Ello pone de manifiesto, por si hubiera dudas, que tal modelo nace y se desarrolla a partir de presupuestos jurídico-políticos conectados con una cultura de la tolerancia y del respeto de los modelos de vida diferentes de los propios, ${ }^{39}$ lo cual supone, a su vez, un juicio de valor de carácter positivo acerca de la tolerancia y del respeto de todos los modelos de vida, $\mathrm{y}$ - al contrario - un juicio negativo de la intolerancia y de toda forma de fundamentalismo (cultural, religioso, político, moral). No se piense, sin embargo, que el modelo "blando" pueda constituir una panacea, ni siquiera en el ámbito limitado de la bioética, pues probablemente en algunos sectores de ésta puede ser recomendable un modelo diferente. ${ }^{40}$ Sin lugar a dudas, el modelo "fuerte", en sus variables prohibicionista y obligatoria es el que mejor "funciona" en determinados sectores de la vida social; en el fiscal, por ejemplo. De igual forma, la tolerancia y el respeto de todo modelo de vida tampoco constituyen principios indiscutibles válidos una vez y para siempre. La inquietante pregunta de cómo comportarse frente al intolerante $\mathrm{y}$ al fundamentalista pende siempre como una espada de Damocles sobre nuestras reflexiones. Todo ello, a mi juicio, en el caso específico del aborto no significa que vengan a menos las virtudes del modelo "blando"; por el contrario, pone en evidencia cómo, más allá de la reflexión teórica destinada a la conformación de modelos de conducta, la filosofía moral se ve

39 Es decir, usando los términos de Rodolfo Vázquez, en el marco de una ética de corte liberal. Véase R. Vázquez, "Una justificación liberal de la clonación”, en id. (comp.), Bioética y derecho. Fundamentos y problemas actuales, ya citado, pp. 201-213. Vázquez explícitamente conecta los presupuestos teóricos de esta concepción con Carlos S. Nino, Ética y derechos humanos, Astrea, Buenos Aires, 1989, y con Max Charlesworth, La bioética en una sociedad liberal, Cambridge University Press, 1996.

40 Pienso, por ejemplo, en las moratorias impuestas en el campo de la clonación humana, al menos hasta que la experimentación con animales no humanos no haya sido conducida a un estadio en el que se puedan excluir de modo razonable los riesgos conexos a tal práctica. 
obligada continuamente a discutir una y otra vez los presupuestos de una ética particular, colocándose también, por la fuerza de las cosas, en una perspectiva metateórica y metaética. Y así, esto da forma a una prosecución ininterrumpida $-\mathrm{y}$ valiosa desde un punto de observación tanto práctico cuanto teórico- de interacciones recíprocas entre la ética y la metaética.

\section{EL MODELO “BLANDO” DE REGULACIÓN JURÍDICA: ASPECTOS CRÍTICOS}

¿Es el modelo de regulación jurídica que se ha dado en llamar "blando" mejor que el modelo "fuerte"? De lo que hasta aquí se ha hecho evidente, podrían quizá generarse dos equívocos que es necesario examinar. Por un lado, alguien podría creer que, de lo que he dicho, se desprende la idea de que a esta pregunta se le puede dar una respuesta absoluta. Por el otro, se podría también pensar que, en consecuencia, yo considere mejor el modelo "blando".

En lo que respecta al primer punto, nada más lejos de mis intenciones que afirmar que se pueda responder a la pregunta en cuestión con un 'si' o un 'no' de manera tajante. En primer lugar, porque el modelo "blando" y también el modelo "fuerte" no constituyen, como ya he aclarado antes, modelos que puedan funcionar en todo un orden jurídico. De manera que la única respuesta sensata a la pregunta comienza a fortiori con un prudente "depende". Depende, es evidente, del sector de la vida social que el derecho se prepara a regular. En consecuencia, es más adecuado, probablemente, hablar no de modelos, sino de modalidades regulativas, para acentuar su carácter regulatorio parcial y no global. El modelo "blando" parecería ser más conveniente, en el sentido de que comporta un menor "desgaste" social en aspectos caracterizados por una evidente valencia moral, entre los que el caso específico del aborto constituye el paradigma más evidente. Al no prohibir ni obligar a abortar, el modelo "blando" se coloca en una posición equidistante entre las posiciones morales que crean el conflicto, no optando por alguna solución que imponga una respuesta moral única.

Ahora puedo pasar al segundo punto, que, como se puede ver, está en estrecha conexión con el primero. Mi preferencia por el modelo "blando" o, mejor dicho, modalidad de regulación jurídica excluye cualquier consideración de carácter absoluto en cuanto a su "bondad". En ciertos casos, como en el del aborto, soy de la opinión de que esta modalidad de regulación (permitiéndolo condicionadamente, no prohibiéndolo ni haciéndolo obligatorio) es la más adecuada para nuestras sociedades modernas, siempre cada vez más caracterizadas por el pluralismo moral. En otros casos, como en el aspecto fiscal, la modalidad "blanda" de regulación sería extremadamente conveniente para quien piensa que el funcionamiento del Estado y su aparato técnico-administrativo no es un aspecto monetario que le competa: 
pero la bancarrota del Estado a la que conduciría la implantación del carácter optativo de los impuestos (los paga quien así lo desee) no sería a final de cuentas un resultado financiero muy brillante. Lo anterior significa que la prudencia del "depende" no se aplica sólo atendiendo a la particularidad de la situación social que se regule y de la que depende la opción por una modalidad regulativa u otra, sino también considerando atentamente todo lo que concierne a la misma situación.

Me he pronunciado contra la simple consideración moral del aborto, pues me parece que la esfera en la que se circunscribiría la discusión puede conducir a la rigidez de las posiciones en conflicto. He sostenido, en efecto, que atenerse al aspecto moral del aborto no nos lleva a ninguna parte, ya que no hay razones suficientes para argumentar en forma conclusiva por una posición u otra, de manera que se pueda zanjar de una vez por todas la cuestión. Bajo esta tesis metaética, no objetivista y no cognitivista, no subyace, sin embargo, una rígida posición irracional en lo que toca a los valores; por el contrario, estoy convencido de que la confrontación racional es posible dentro de un marco teórico que reconozca los límites del discurso racional. Tales límites, como es claro, no son evidentes en la esfera de las valoraciones cotidianas que una persona expresa cuando, tal vez de manera no consciente, justifica sus acciones con base en metavalores que reconoce como "mejores". Por el contrario, es al recorrer esta "escalera" justificativoracional de manera ascendente, para llegar a los valores últimos, cuando la racionalidad humana muestra sus propios límites, ya que ulteriormente no se puede justificar un valor último y es entonces cuando aflora en todo su dramatismo la esfera subjetiva, por fuerza parcial, de nuestro universo de valores; es ahí, en efecto, donde los individuos se encuentran completamente solos ("desnudos", alguien ha dicho) frente a la alternativa moral.

En el caso del aborto, que configura una cuestión que toca nuestros valores últimos — relativos a la idea de vida y de muerte-, cuando llegamos al punto en el que a un principio último se opone otro principio último, entra en crisis, en mi opinión, una idea absoluta de racionalidad; y se hace entonces necesario dar un paso atrás, descender hacia una racionalidad "defectuosa" (o "imperfecta") que nos permita, no obstante, en un universo pluralista, dar cuenta de las razones que sustentan nuestra opción valorativa. Es ahí donde una visión teleológica, y no deontológica, que toma en cuenta los resultados de las opciones valorativas en conflicto y no sólo el deber ser absoluto, puede sernos de utilidad. La modalidad "blanda" de regulación del aborto, vista desde una perspectiva teleológica, no impone una moral particular mediante el derecho positivo, y en una sociedad pluralista esto no es de poca monta. También, al poner las bases para que las mujeres que decidan abortar lo hagan de manera segura, se puede poner 
fin al drama del aborto clandestino, sin que ello signifique, a largo plazo, un aumento en el número total de abortos, como así lo demuestran las estadísticas allá donde hoy existe una regulación jurídica de este tipo. Además, y esto se conecta con el punto anterior, desde un punto de vista estrictamente socio-jurídico, la modalidad "blanda", en cuanto que permite que aborte la mujer que lo desee, elimina la conflictividad jurídica que el modelo "fuerte" irremediablemente contiene. La prohibición dentro de una modalidad "fuerte" no impide, en efecto, que muchas mujeres de cualquier manera decidan abortar, a pesar del riesgo de la coacción; y aunque de hecho el delito de aborto puede ser muy poco perseguido por quienes ejercen la justicia, de cualquier manera esas mujeres — y quienes las "ayudan" — saben bien que su acto de abortar puede ser penalizado en cualquier momento, dependiendo de la voluntad contingente, como un delito. En consecuencia, permitir el aborto ayuda a destruir la ficción jurídica que está detrás de la idea ingenua de que es suficiente prohibir un comportamiento - $\mathrm{O}$ bien, obligar a las personas a comportarse de algún modo-con una norma jurídica para que se obtenga el resultado deseado. Como recomiendan los buenos juristas, el derecho no debería prohibir comportamientos necesarios (como la respiración, por ejemplo), ni hacer obligatorios actos imposibles (como volar sin la ayuda de aeroplanos o aparatos semejantes). El aborto no constituye, por fortuna, ni un evento necesario, ni, por desgracia, un evento imposible; es sólo el último y desesperado recurso —el mal menor-que muchas mujeres consideran como alternativa en un determinado momento de su vida. ¿Cómo regularlo jurídicamente, más allá de todas nuestras elucubraciones filosófico-teóricas?

Recibido el 23 de octubre de 2000; revisado el 2 de julio de 2001; aceptado el 19 de septiembre de 2001 